\title{
Exploring the Potential of a Wearable Camera to Examine the Early Obesogenic Home Environment: Comparison of SenseCam Images to the Home Environment Interview
}

Stephanie Schrempft ${ }^{1}, \mathrm{PhD}$; Cornelia HM van Jaarsveld ${ }^{2,3}, \mathrm{PhD}$; Abigail Fisher ${ }^{1}, \mathrm{PhD}$

${ }^{1}$ Department of Behavioural Science and Health, University College London, London, United Kingdom

${ }^{2}$ Department for Health Evidence, Radboud University Medical Center, Nijmegen, Netherlands

${ }^{3}$ Department of Primary and Community Care, Radboud University Medical Center, Nijmegen, Netherlands

Corresponding Author:

Abigail Fisher, PhD

Department of Behavioural Science and Health

University College London

1-19 Torrington Place

London,

United Kingdom

Phone: 4402076791722

Email: abigail.fisher@ucl.ac.uk

\section{Abstract}

Background: The obesogenic home environment is usually examined via self-report, and objective measures are required.

Objective: This study explored whether the wearable camera SenseCam can be used to examine the early obesogenic home environment and whether it is useful for validation of self-report measures.

Methods: A total of 15 primary caregivers of young children (mean age of child 4 years) completed the Home Environment Interview (HEI). Around 12 days after the HEI, participants wore the SenseCam at home for 4 days. A semistructured interview assessed participants' experience of wearing the SenseCam. Intraclass correlation coefficients (ICCs), percent agreement, and kappa statistics were used as validity estimates for 54 home environment features.

Results: Wearing the SenseCam was generally acceptable to those who participated. The SenseCam captured all 54 HEI features but with varying detail; 36 features $(67 \%$ ) had satisfactory validity (ICC or kappa $\geq 0.40$; percent agreement $\geq 80$ where kappa could not be calculated). Validity was good or excellent (ICC or kappa $\geq 0.60$ ) for fresh fruit and vegetable availability, fresh vegetable variety, display of food and drink (except sweet snacks), family meals, child eating lunch or dinner while watching TV, garden and play equipment, the number of TVs and DVD players, and media equipment in the child's bedroom. Validity was poor (ICC or kappa <0.40) for tinned and frozen vegetable availability and variety, and sweet snack availability.

Conclusions: The SenseCam has the potential to objectively examine and validate multiple aspects of the obesogenic home environment. Further research should aim to replicate the findings in a larger, representative sample.

(J Med Internet Res 2017;19(10):e332) doi: 10.2196/jmir.7748

\section{KEYWORDS}

environment and public health; obesity; parents

\section{Introduction}

The home environment is thought to play an important role in early obesity prevention and weight management [1-3]. Researchers have identified food, physical activity, and media-related influences as core domains that define the obesogenic home environment [4]. Multiple self-report measures have been used to examine aspects within home environment domains, but few are comprehensive, and few have been assessed in terms of criterion validity (the extent to which they relate to concrete criteria in the real world) [5]. The Home Environment Interview (HEI) is one of few comprehensive home environment measures and has recently been associated with diet, physical activity, and TV viewing in a large sample of preschool children [6]. 
Demonstrating the criterion validity of parent- or self-reported measures (which are prone to social desirability and recall biases) is important to ensure that the results of studies using them are largely unattributable to measurement error. In the case of the home environment, identifying accurate associations with health behaviors and/or weight is important for ensuring the design of effective weight-related interventions. Studies that have assessed criterion validity have tended to use one-off home visits that cannot capture behavioral or social aspects of the home environment, such as mealtime interactions and parental modeling [7]. Multiple home visits can provide further insight [8], but they are costly and labor intensive.

Technologic advances have provided opportunities to objectively examine the obesogenic home environment. Video recording has long been used by developmental researchers to assess child-parent interactions, including those at mealtimes [9-11]. Disposable cameras have been used to capture the food environment from the child's perspective [12]. Although insightful, standard picture cameras do not permit continuous recording and video cameras do not capture events from the first-person perspective, which would provide a more detailed and naturalistic account of an individual's environment.

Visual lifelogging refers to the passive digital capture of everyday activities from the first-person perspective. Numerous devices have been developed for visual lifelogging [13]. The most popular wearable camera in a research setting is the SenseCam (Microsoft Corp) [14], designed to take pictures automatically (approximately every 20 seconds) when triggered by sensors that log temperature, light, acceleration, and passive infrared data [15]. The SenseCam is straightforward to use, has a long battery life (up to 16 hours), a large storage capacity (over one week's worth of images), a wide-angle lens to capture everything within the wearer's view, and does not record sound [16]. Each image is time-stamped so duration of specific events or activities can be deduced.

The SenseCam has predominantly been used in memory and cognitive impairment research $[17,18]$. More recent research has explored how the SenseCam can be used to assess diet and activity behaviors. SenseCam images have been compared with travel diaries in volunteer adults [19] and teenagers [20], food diaries [21], 24-hour dietary recall [22], and accelerometers in university employees to improve the classification of sedentary behavior [23], highlighting the utility of a wearable camera to validate traditional assessment tools. The SenseCam has also been used to examine the context of eating behavior in adult [24] and teenage [25] participants. No studies have used a wearable camera to examine the early obesogenic home environment.

This study will therefore examine whether the wearable camera SenseCam can be used to examine the early obesogenic home environment and whether it is useful for validation of self-report measures. Specifically, this study will examine whether the Sensecam is acceptable to participants, which aspects of the obesogenic home environment can be captured by the SenseCam, and how this information compares to that captured by the HEI [6].

\section{Methods}

\section{Study Sample}

The study sample was obtained using convenience sampling. Participants were 15 parents of children aged 2 to 8 years who had taken part in previous research at University College London and agreed to be contacted for future studies. A total of 94 parents were sent an invitation letter. Parents who did not respond to the letter were followed up with a telephone call. Participants gave written consent before taking part. Any other adults living in the home also consented to participation, since they would be photographed. Ethical approval for the study was granted by the University College London Ethics Committee for Research Involving Human Subjects (project approval number 3792/001). The study protocol adhered to the ethical framework outlined by Kelly and colleagues [26].

\section{Measuring and Validating the Home Environment}

Participants completed the HEI by telephone while at home. The HEI is one of few comprehensive measures of the home environment, capturing multiple aspects of the food, physical activity, and media domains. Items assess food availability and accessibility, physical activity opportunities, and media equipment availability, as well as social aspects such as parental modeling of eating and activity behaviors. The HEI was adapted from the Healthy Home Survey [7], the most comprehensive home environment measure available at the time, and with evidence for criterion validity [7]. Consistent with the Healthy Home Survey, the test-retest reliability of the HEI (assessed in a sample of 44 parents) was generally moderate to high. The intraclass correlation coefficients (ICCs) and 95\% confidence intervals for the total scores were as follows: food environment $(0.71,0.52-0.83)$, activity environment $(0.83,0.72-0.91)$, media environment (0.92, 0.85-0.95), and overall (0.92, 0.86-0.96). Additional details of the HEI are provided in a previous publication [6].

Participants were visited at home on average 12 (SD 5.82) days after completing the HEI. The time frame between completing the HEI and wearing the camera was chosen to be largely consistent with the validation study of the Healthy Home Survey, where the home visit took place 7 to 14 days after the initial telephone interview. Participants were asked to wear the camera during waking hours while at home for 4 consecutive days (including at least one weekend day). A 4-day wearing period was chosen to strike a balance between capturing sufficient information about the home environment for the purposes of the study and minimizing participant burden. Participants wore the SenseCam on a lanyard around their neck with adhesive fashion tape attached to the back to reduce movement. Participants were told that they were free to turn off or remove the camera whenever they did not feel comfortable wearing it. The following statement was provided for participants to use if they encountered other people while wearing the camera: "I am volunteering for a research project looking at my home environment. The device is called SenseCam and it takes pictures of my daily activities." Previous research has found that this approach is sufficient to satisfy any queries from other members of the public [19]. 


\section{Semistructured Interview}

After the wearing period, the camera was collected and participants completed a semistructured interview. Participants were asked about ease of use, awareness of the camera, reactions from other people, instances where they did not feel comfortable wearing the camera, and whether they felt that wearing the SenseCam could influence families to change aspects of their household routine. Participants had the opportunity to view and delete their images if they did not wish to have them stored for analysis.

\section{Statistical Analysis}

The SenseCam images were manually coded using the Oxford CLARITY-DCU SenseCam browser [27]. Each image was visually inspected and coded for the presence or absence of features assessed in the HEI. Home environment features that could not be captured by the SenseCam were identified before coding and included whether the child was allowed to help him or herself to food and drink; the frequency the child was allowed to play inside and outside the home; parks and indoor recreation centers close to the home; and rules around media use. A total of 54 features were coded (42 food-, 2 activity-, and 10 media-related). These are shown in Tables 2 and 3 and in Multimedia Appendix 1 alongside the corresponding HEI questions.

Images were classified as uncodeable if there were low light levels, something was covering the lens, or in cases of extreme blurring. Home environment features were coded as missing if they were not identifiable in the images.
A total of 60 days of data (75,818 images) were coded. It took 100 hours to code the data. One randomly selected day's worth of images was recoded by the original coder after study completion to assess intrarater reliability. For interrater reliability, an independent coder analyzed another randomly selected day's worth of images. There was almost 100\% agreement across coding sessions.

ICCs (for continuous variables), percent agreement, and kappa statistics (for categorical variables) were used as validity estimates. As recommended, kappas and ICCs were defined as: $<0.40=$ poor, $0.40-0.59=$ fair, $0.60-0.74=$ good, and $0.75-1.00=$ excellent [28]. In cases where percent agreement was high $(\geq 80)$ but kappa was poor, the proportion of positive (ppos) and negative (pneg) agreement were presented. This is recommended for better understanding of results [29].

\section{Results}

\section{Study Sample}

Of the 94 parents contacted, 34 (36\%) did not respond to the initial letter and could not be contacted by telephone or email. Among those who responded and did not wish to participate in the study, $62 \%$ (28/45) cited discomfort with wearing the camera as the reason and $38 \%(17 / 45)$ cited other reasons such as lack of time. Participants included 13 mothers and 2 fathers. All were main caregivers of their children. Parent and child characteristics are shown in Table 1. 
Table 1. Characteristics of families who took part in the study.

\begin{tabular}{|c|c|}
\hline Characteristics & Mean (SD) or $\mathrm{n}(\%)$ \\
\hline \multicolumn{2}{|l|}{ Parent characteristics } \\
\hline Age (years), mean (SD) & $38.6(6.4)^{\mathrm{a}}$ \\
\hline \multicolumn{2}{|l|}{ Education level $^{\mathbf{b}}, \mathrm{n}(\%)$} \\
\hline Low & $1(7)$ \\
\hline Medium & $2(13)$ \\
\hline High & $12(80)$ \\
\hline \multicolumn{2}{|l|}{ Ethnicity, n (\%) } \\
\hline White & $13(87)$ \\
\hline Other & $2(13)$ \\
\hline \multicolumn{2}{|c|}{ Number of children in the home, $n(\%)$} \\
\hline One & $5(33)$ \\
\hline More than one & $10(67)$ \\
\hline \multicolumn{2}{|l|}{ Child characteristics } \\
\hline Age (years), mean (SD) & $4.8(1.7)$ \\
\hline \multicolumn{2}{|l|}{$\operatorname{Sex}, \mathbf{n}(\%)$} \\
\hline Male & $10(67)$ \\
\hline Female & $5(33)$ \\
\hline \multicolumn{2}{|l|}{ Ethnicity, n (\%) } \\
\hline White & $9(60)$ \\
\hline Other & $6(40)$ \\
\hline
\end{tabular}

${ }^{\mathrm{a}}$ Data were missing for 1 participant on this variable $(\mathrm{n}=14)$.

${ }^{b}$ Education level categorized as low (no qualifications or basic high school education), medium (vocational or advanced high school education), and high (university-level education). 
Table 2. Descriptive statistics for the home environment features ( $\mathrm{N}=15 ; \mathrm{n}[\%]$ who responded yes or mean [SD]).

\begin{tabular}{|c|c|c|}
\hline Home environment feature & $\mathrm{HEI}^{\mathrm{a}}$ & SenseCam \\
\hline \multicolumn{3}{|l|}{ Food availability, n (\%) } \\
\hline Fresh fruit & $15(100)$ & $15(100)$ \\
\hline Tinned fruit & $6(40)$ & $0(0)$ \\
\hline Dried fruit & $9(60)$ & $4(27)$ \\
\hline Frozen fruit & $3(20)$ & $0(0)$ \\
\hline Fresh vegetables & $14(93)$ & $15(100)$ \\
\hline Tinned vegetables & $14(93)$ & $7(47)$ \\
\hline Frozen vegetables & $13(87)$ & $4(27)$ \\
\hline Savory snacks & $10(67)$ & $8(53)$ \\
\hline Sweet snacks & $12(80)$ & $6(40)$ \\
\hline Confectionery & $10(67)$ & $4(27)$ \\
\hline Fruit juice & $8(53)$ & $11(73)$ \\
\hline Squash & $5(33)$ & $4(27)$ \\
\hline Fizzy drinks & $2(13)$ & $4(27)$ \\
\hline Smoothies & $3(20)$ & $1(7)$ \\
\hline Skimmed/semiskimmed milk & $10(67)$ & $13(87)$ \\
\hline Full-fat milk & $5(33)$ & $6(40)$ \\
\hline \multicolumn{3}{|l|}{ Food variety, mean (SD) } \\
\hline Fresh fruit & $3.5(1.4)$ & $4.5(2.3)$ \\
\hline Tinned fruit & $0.6(0.9)$ & $0(0)$ \\
\hline Dried fruit & $1.9(1.9)$ & $0.3(0.6)$ \\
\hline Frozen fruit & $0.2(0.4)$ & $0(0)$ \\
\hline Fresh vegetables & $6.3(3.0)$ & $6.7(3.1)$ \\
\hline Tinned vegetables & $3.9(1.7)$ & $0.8(1.0)$ \\
\hline Frozen vegetables & $1.7(1.4)$ & $0.3(0.5)$ \\
\hline Savory snacks & $1.1(1.1)$ & $0.7(0.7)$ \\
\hline Sweet snacks & $1.5(1.1)$ & $0.7(1.1)$ \\
\hline Confectionery & $0.9(0.8)$ & $0.3(0.5)$ \\
\hline \multicolumn{3}{|l|}{ Food displayed, n (\%) } \\
\hline Any fruit & $15(100)$ & $14(93)$ \\
\hline Ready-to-eat vegetables & $2(13)$ & $0(0)$ \\
\hline Savory snacks & $0(0)$ & $0(0)$ \\
\hline Sweet snacks & $3(20)$ & $2(13)$ \\
\hline Confectionery & $1(7)$ & $1(7)$ \\
\hline Fruit juice & $0(0)$ & $0(0)$ \\
\hline Squash & $2(13)$ & $3(20)$ \\
\hline Fizzy drinks & $1(7)$ & $0(0)$ \\
\hline Smoothies & $0(0)$ & $0(0)$ \\
\hline \multicolumn{3}{|l|}{ Family meals, n (\%) } \\
\hline Breakfast & $11(73)$ & $11(73)^{b}$ \\
\hline Lunch & $12(80)$ & $10(67)^{\mathrm{c}}$ \\
\hline
\end{tabular}




\begin{tabular}{|c|c|c|}
\hline Home environment feature & $\mathrm{HEI}^{\mathrm{a}}$ & SenseCam \\
\hline Dinner & $11(73)$ & $12(80)^{b}$ \\
\hline \multicolumn{3}{|l|}{ Child eating while watching TV, n (\%) } \\
\hline Breakfast & $0(0)$ & $2(13)^{\mathrm{d}}$ \\
\hline Lunch & $0(0)$ & $0(0)^{\mathrm{e}}$ \\
\hline Dinner & $1(7)$ & $1(7)^{\mathrm{d}}$ \\
\hline Snacks & $5(33)$ & $2(13)^{\mathrm{f}}$ \\
\hline \multicolumn{3}{|l|}{ Activity facilities, n (\%) } \\
\hline Garden & $12(80)$ & $10(67)$ \\
\hline Garden equipment & $2(17)$ & $1(8)^{\mathrm{g}}$ \\
\hline \multicolumn{3}{|l|}{ Household media equipment, mean (SD) } \\
\hline Number of TVs & $1.5(1.1)$ & $1.6(1.1)$ \\
\hline Number of VCR/DVD players & $1.5(1.0)$ & $1.3(0.9)$ \\
\hline Number of computers & $2.4(1.0)$ & $1.6(0.9)$ \\
\hline Number of games consoles & $0.7(1.0)$ & $0.2(0.6)$ \\
\hline Presence of cable or satellite, n (\%) & $9(60)$ & $3(20)^{\mathrm{h}}$ \\
\hline \multicolumn{3}{|l|}{ Child's bedroom media equipment, n (\%) } \\
\hline $\mathrm{TV}$ & $2(13)$ & $3(20)^{\mathrm{i}}$ \\
\hline Computer & $1(7)$ & $1(7)^{\mathrm{i}}$ \\
\hline Console & $2(13)$ & $1(7)^{\mathrm{i}}$ \\
\hline \multicolumn{3}{|l|}{ Caregiver TV viewing (hours), mean (SD) } \\
\hline Weekday & $1.7(1.3)$ & $1.2(0.7)^{\mathrm{j}}$ \\
\hline Weekend & $2.4(1.67)$ & $1.5(0.81)^{\mathrm{k}}$ \\
\hline
\end{tabular}

${ }^{\mathrm{a}} \mathrm{HEI}$ : Home Environment Interview.

${ }^{\mathrm{b}}$ Two cases were coded as missing: 1 participant did not wear the SenseCam during breakfast time and 1 participant said during the semistructured interview that they had modified their mealtime routine.

${ }^{\mathrm{c}}$ Three cases were coded as missing: 2 participants did not wear the SenseCam during lunchtime and 1 participant had modified their mealtime routine. ${ }^{\mathrm{d}}$ Data were missing in 3 cases: 1 did not wear the SenseCam at breakfast/dinner time, 1 said in the semistructured interview that they had modified their mealtime routine, and the third did not have breakfast/dinner with their children during the wearing period.

${ }^{\mathrm{e}}$ Data were missing in 5 cases: 2 did not wear the SenseCam at lunchtime, 1 said that they had modified their mealtime routine, and the last 2 did not have lunch with their children during the wearing period.

${ }_{\mathrm{f}}$ Data were missing in 1 case where the caregiver did not wear the SenseCam around their child.

${ }^{\mathrm{g}}$ Three cases were coded as missing as the garden wasn't fully visible during the wearing period.

${ }^{h}$ It was only possible to determine the presence or absence of cable or satellite in 4 cases; the remaining cases were coded as missing.

${ }^{\mathrm{i}}$ Two cases were coded as missing because the child's bedroom was not visible during the wearing period.

${ }^{\mathrm{j}}$ Data were missing in 6 cases where the caregiver did not wear the SenseCam for all of the weekday periods (morning/afternoon/evening).

${ }^{\mathrm{k}}$ Data were missing in 7 cases where the caregiver did not wear the SenseCam for all of the weekend periods (morning/afternoon/evening).

\section{Measuring and Validating the Home Environment}

Participants wore the SenseCam for 4 (SD 1.1) days on average. The average wearing time per day was 5.9 (SD 2.6) hours . All 54 home environment features were captured to some extent. What was captured by the SenseCam depended on the duration of the wearing period and participant behavior during this period. As shown in Table 2, fresh fruit and vegetables were captured in all cases, tinned and frozen foods were rarely captured, and energy-dense snacks were captured to a slightly less extent than reported in the HEI. In almost all cases, it was not possible to determine the sugar content of drinks. It was possible to identify milk type using the color of the bottle tops. The presence of satellite TV was rarely captured, and child snacking while watching TV was captured less frequently than reported in the HEI. In total, 4470 images (6\%) were classified as uncodeable. Figure 1 shows some sample images of home environment features. 
Figure 1. Sample SenseCam images showing the presence of confectionery (left), a family dinner (center), and eating breakfast while watching TV (right). Faces are colored for anonymity.

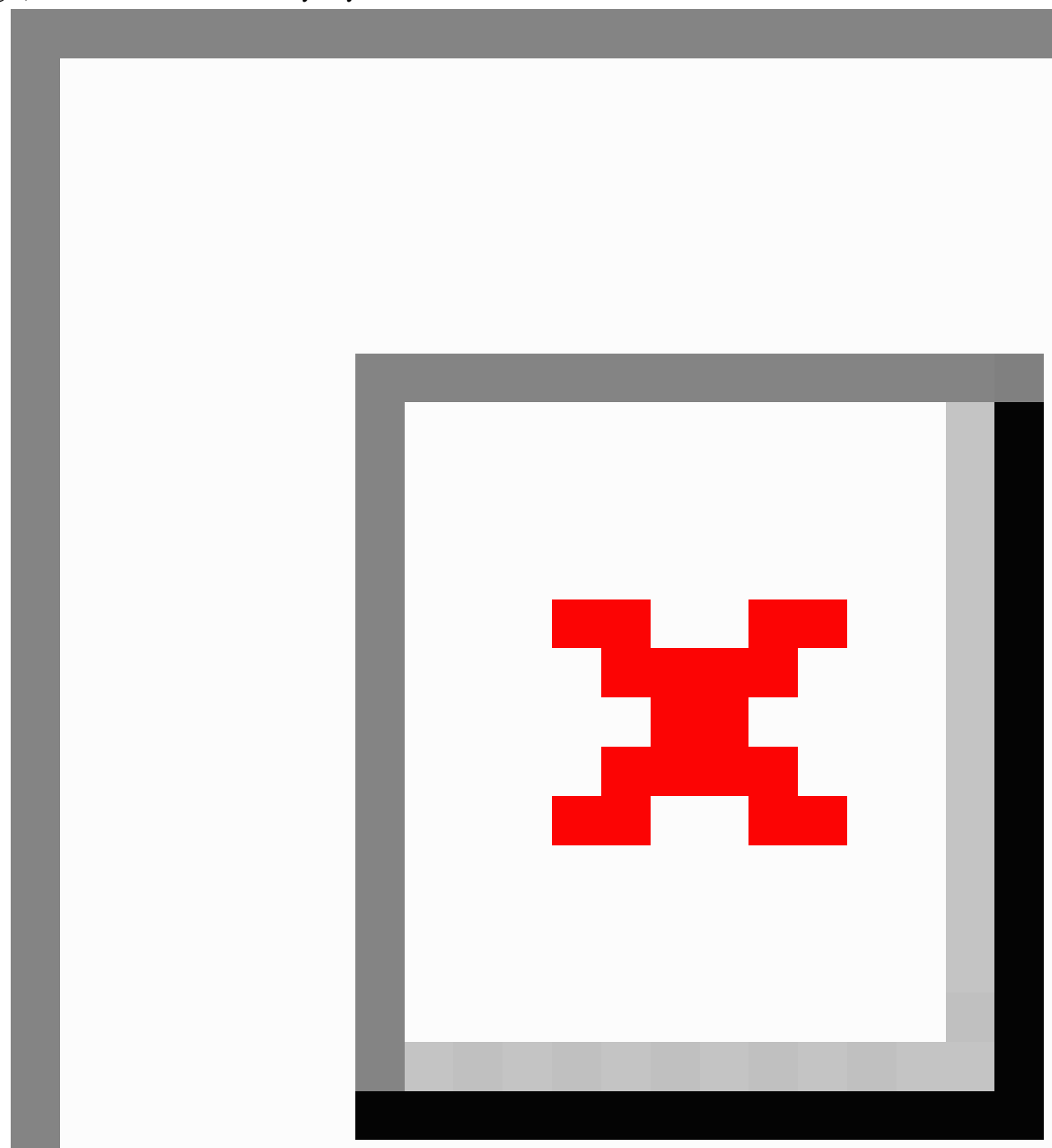

Validity estimates for the 42 home food environment variables are shown in Table 3. Of the 42 variables, $25(60 \%)$ had satisfactory validity (ICC or kappa $\geq 0.40$; percent agreement $\geq 80$ where kappa could not be calculated). Validity estimates were good for fresh fruit, fresh vegetable, and full-fat milk availability, the variety of fresh vegetables, the display of food and drink (except sweet snacks), eating meals as a family, and child eating lunch/dinner while watching TV. Particularly low validity estimates were reported for tinned and frozen vegetable availability and variety, and sweet snack availability. For the display of confectionery, percent agreement was high (87\%), but kappa was -0.07 because there was just one yes response

at the time of the HEI and one yes response captured by SenseCam (ppos was 0.00, but pneg was 0.93).

Validity estimates for the home activity and media environment variables are also shown in Table 3. The presence of a garden and play equipment had good validity (kappa $>0.60$ ). Of the 10 home media environment variables, $9(90 \%)$ had satisfactory validity and $5(50 \%)$ had good or excellent validity. Validity was lower for the number of household computers (ICC 0.3).

\section{Semistructured Interview}

All but 1 participant completed the semistructured interview. All completing participants said that the SenseCam was straightforward to use. Initially, 1 participant had trouble 
charging the camera, and 2 forgot to charge it. Two participants said that the camera sometimes got in the way when they carried their children. Another suggested using a smaller, more discreet camera.

A total of 7 participants said that they forgot to wear the camera on some occasions: when they were returning from an outing, rushing in the morning to get ready for work, or when their children were not around. Situations where participants said they chose not to wear the SenseCam included trips to the bathroom, getting their children ready for bed, and when they had a visitor.

Almost all participants said that wearing the SenseCam made them think about aspects of their behavior and household routines. For example, one of the participants felt that their children were not eating healthily, watched too much TV, and needed to do more constructive activities. Although participants reported that they were aware of their behavior, most said that wearing the camera did not modify it. Two participants said that wearing the camera did affect their behavior: 1 said that they made more of an effort to eat with their child, and the other said that they tried to have meals at the table instead of while watching TV.

Participants generally reported that they were less aware of the camera as time went on. All participants reported that their children were interested in the camera, although this lessened with time. One participant said that their child was initially shy around the camera, and 1 thought that their children behaved better than usual.

Overall, participants were generally positive about the camera. A third of the participants said that they would be happy to wear the camera for a longer period of 1 to 2 weeks; the remaining participants felt that 4 days was sufficient. All participants felt that the SenseCam may be helpful to families that need to change aspects of their behavior or household routine. 
Table 3. Validity estimates for the home environment features $(\mathrm{N}=15)$.

\begin{tabular}{|c|c|c|c|}
\hline Home environment feature & Intraclass correlations $(95 \% \mathrm{CI})$ & Kappa $(95 \%$ CI) & $\%$ Agreement \\
\hline \multicolumn{4}{|l|}{ Food availability } \\
\hline Fresh fruit $^{\mathrm{a}}$ & - & $-\mathrm{b}$ & 100 \\
\hline Tinned fruit & - & $-\mathrm{b}$ & 60 \\
\hline Dried fruit & - & $0.39(0.06$ to 0.72$)$ & 67 \\
\hline Frozen fruit $^{\mathrm{a}}$ & - & $-{ }^{b}$ & 80 \\
\hline Fresh vegetables ${ }^{\mathrm{a}}$ & - & $-\mathrm{b}$ & 93 \\
\hline Tinned vegetables & - & $0.12(-0.11$ to 0.35$)$ & 53 \\
\hline Frozen vegetables & - & $0.11(-0.09$ to 0.30$)$ & 40 \\
\hline Savory snacks ${ }^{\mathrm{a}}$ & - & 0.45 (0.04 to 0.87$)$ & 73 \\
\hline Sweet snacks & - & $0.13(-0.07$ to 0.32$)$ & 33 \\
\hline Confectionery & - & $0.31(-0.07$ to 0.69$)$ & 60 \\
\hline Fruit juice $^{\mathrm{a}}$ & - & $0.59(0.16$ to 1.01$)$ & 80 \\
\hline Squash $^{\mathrm{a}}$ & - & 0.51 (0.06 to 0.97$)$ & 80 \\
\hline Fizzy drinks & - & $0.19(-0.35$ to 0.72$)$ & 73 \\
\hline Smoothies $^{\mathrm{a}}$ & - & $0.44(-0.17$ to 1.06$)$ & 87 \\
\hline Skimmed/semi-skimmed milk ${ }^{\mathrm{a}}$ & - & 0.47 (0.07 to 0.88$)$ & 80 \\
\hline Full-fat milk ${ }^{\mathrm{a}}$ & - & $0.73(0.41$ to 1.04$)$ & 87 \\
\hline \multicolumn{4}{|l|}{ Food variety } \\
\hline Fresh fruit $^{\mathrm{a}}$ & $0.43(-0.09$ to 0.76$)$ & - & - \\
\hline Tinned fruit & $-^{\mathrm{b}}$ & - & - \\
\hline Dried fruit & $0.19(-0.34$ to 0.63$)$ & - & - \\
\hline Frozen fruit & $-\mathrm{b}$ & - & - \\
\hline Fresh vegetables $^{\mathrm{a}}$ & $0.72(0.35-0.90)$ & - & - \\
\hline Tinned vegetables & $0.28(-0.25$ to 0.68$)$ & - & - \\
\hline Frozen vegetables & $0.00(-0.49$ to 0.50$)$ & - & - \\
\hline Savory snacks & $0.37(-0.15$ to 0.73$)$ & - & - \\
\hline Sweet snacks ${ }^{\mathrm{a}}$ & $0.46(-0.04$ to 0.78$)$ & - & - \\
\hline Confectionery & $0.38(-0.14$ to 0.74$)$ & - & - \\
\hline \multicolumn{4}{|l|}{ Food displayed } \\
\hline Any fruit ${ }^{\mathrm{a}}$ & - & $-\mathrm{b}$ & 93 \\
\hline Ready-to-eat vegetables ${ }^{\mathrm{a}}$ & - & $-\mathrm{b}$ & 87 \\
\hline Savory snacks ${ }^{\mathrm{a}}$ & - & $-{ }^{b}$ & 100 \\
\hline Sweet snacks & - & $-0.19(-0.40$ to 0.02$)$ & 67 \\
\hline Confectionery $^{\mathrm{a}}$ & - & $-0.07(-0.19 \text { to } 0.05)^{\mathrm{c}}$ & 87 \\
\hline Fruit juice $^{\mathrm{a}}$ & - & $-{ }^{b}$ & 100 \\
\hline Squash $^{\mathrm{a}}$ & - & $0.76(0.26$ to 1.26$)$ & 93 \\
\hline Fizzy drinks $^{\mathrm{a}}$ & - & ${ }^{\mathrm{b}}$ & 93 \\
\hline Smoothies ${ }^{\mathrm{a}}$ & - & $-^{b}$ & 100 \\
\hline
\end{tabular}




\begin{tabular}{|c|c|c|c|}
\hline Home environment feature & Intraclass correlations $(95 \% \mathrm{CI})$ & Kappa $(95 \%$ CI) & $\%$ Agreement \\
\hline \multicolumn{4}{|l|}{ Family meals } \\
\hline Breakfast $^{\mathrm{a}}$ & - & $-{ }^{b}$ & 100 \\
\hline Lunch $^{\mathrm{a}}$ & - & $-\mathrm{b}$ & 83 \\
\hline Dinner $^{\mathrm{a}}$ & - & $0.63(-0.09$ to 1.35$)$ & 92 \\
\hline \multicolumn{4}{|l|}{ Child eating while watching TV } \\
\hline Breakfast & - & $-\mathrm{b}$ & 77 \\
\hline Lunch $^{\mathrm{a}}$ & - & $-{ }^{b}$ & 92 \\
\hline Dinner $^{\mathrm{a}}$ & - & $0.63(-0.16$ to 1.41$)$ & 92 \\
\hline Snacks & - & $0.10(-0.36$ to 0.57$)$ & 64 \\
\hline \multicolumn{4}{|l|}{ Activity facilities } \\
\hline Garden $^{\mathrm{a}}$ & - & 0.67 (0.26 to 1.07$)$ & 87 \\
\hline Garden equipment ${ }^{\mathrm{a}}$ & - & $0.63(-0.03$ to 1.28$)$ & 92 \\
\hline \multicolumn{4}{|l|}{ Household media equipment } \\
\hline Number of TVs & $0.97(0.92$ to 0.99$)$ & - & - \\
\hline Number of VCR/DVD players ${ }^{\mathrm{a}}$ & $0.82(0.55$ to 0.94$)$ & - & - \\
\hline Number of computers & $0.30(-0.23$ to 0.69$)$ & - & - \\
\hline Number of games consoles ${ }^{\mathrm{a}}$ & $0.55(0.08$ to 0.82$)$ & - & - \\
\hline Presence of cable or satellite ${ }^{a}$ & - & $-{ }^{b}$ & 100 \\
\hline \multicolumn{4}{|l|}{ Child's bedroom media equipment } \\
\hline $\mathrm{TV}^{\mathrm{a}}$ & - & $0.76(0.27$ to 1.25$)$ & 93 \\
\hline Computer $^{\mathrm{a}}$ & - & $-\mathrm{b}$ & 100 \\
\hline Console $^{\mathrm{a}}$ & - & $0.63(-0.06$ to 1.33$)$ & 93 \\
\hline \multicolumn{4}{|l|}{ Caregiver TV viewing (hours) } \\
\hline Weekday $^{\mathrm{a}}$ & $0.55(-0.13$ to 0.88$)$ & - & - \\
\hline Weekend $^{\mathrm{a}}$ & $0.57(-0.15$ to 0.90$)$ & - & - \\
\hline
\end{tabular}

${ }^{\text {a }}$ Feature has satisfactory validity.

${ }^{b}$ ICC was not calculated due to zero variance items or kappa could not be calculated due to cell counts equalling zero.

${ }^{\mathrm{c}}$ There was just one yes response at the time of the HEI and one yes response captured by SenseCam (ppos was 0.00, but pneg was high [0.93]).

\section{Discussion}

\section{Principal Findings}

This study investigated whether a wearable camera can be used to examine the early obesogenic home environment and whether it is useful for validation purposes. The SenseCam captured all 54 home environment features but with varying detail. Features that were captured less frequently included tinned and frozen foods, sweet snacks, and satellite TV. It was not possible to fully capture mealtime and TV viewing behaviors due to there being a single wearer and a limited wearing period. Validity estimates were at least satisfactory for two-thirds of the home environment features. Lower agreement was reported for food variety (except for fresh vegetables) and the number of computers in the home. The SenseCam was generally acceptable to participants, although there were reservations.

While the findings indicate that the SenseCam can be used to examine the obesogenic home environment, a primary issue is that what is captured depends on the actions of the wearer. Although this highlights the utility of the SenseCam as a behavioral measure, it also meant that it was often not possible to determine whether the SenseCam missed a particular feature or whether the feature truly was absent. For most cases of disagreement, a feature was reported at the time of the HEI but not captured by the SenseCam. This was particularly the case for tinned and frozen foods, sweet snacks, and media equipment (excluding TVs). It is possible that certain foods and media equipment were available in the home during the wearing period even though they were not captured. 


\section{Comparison With Prior Work}

Bryant and colleagues [7] reported generally moderate to high agreement when using home visits to validate their Healthy Home Survey. Overall agreement was high for the presence of all food types, suggesting that the low agreement for some food types in our study may indeed have been due to the SenseCam missing this information. Agreement for food variety was also higher than reported in our study. However, lower values (ICCs) were reported for sweet $(0.30)$ and savory $(0.48)$ snack variety in their study, suggesting that some discrepancies in our study may be due to other reasons than the SenseCam missing information, such as natural changes in food availability. As in our study, agreement for the presence of a garden and play equipment was high. For the number of computers and game consoles, agreement was higher than in our study $(65 \%$ and $73 \%$, respectively). However, in our study, it was possible to capture eating and TV viewing behavior, with acceptable agreement given the limited wearing period.

There were some cases of disagreement where a feature was not reported in the HEI but was captured by the SenseCam. For example, 2 participants did not report fizzy drinks, but these were present during the wearing period. It is feasible that these differences were due to natural changes in food availability; however, it could also reflect some bias in responding during the HEI. Previous research comparing self-reports to SenseCam images have found that individuals may overestimate their activity levels [19] and underestimate their dietary intake [21]. To determine whether differences really were due to changes in food availability, it would have been useful to ask participants about their shopping habits during the wearing period.

It is noteworthy that the SenseCam captured fewer sweet snacks than were reported in the HEI while slightly more fresh fruit and vegetables were captured. Although this could be a chance finding, participants may have modified their access to certain foods in the home. However, it is not clear if any behavioral effect would result from wearing the camera, completing the interview, or both. A larger scale validation study could use counter-balancing to control for any potential order effects. Nevertheless, most participants said that although wearing the camera made them reflect about their home environment, they did not think that it affected their behavior. When behavior is habitual, behavioral responses are activated automatically [30].

\section{Limitations}

The large amount of data accumulated by the SenseCam is important to consider. Manual coding is time-consuming and errors can occur, although interrater reliability in this study was high. Automatic coding procedures for the home environment are needed, particularly if research uses longer wearing periods and involves multiple family members.
Another factor to consider is participant recruitment, as many families contacted in this study were not comfortable with the idea of wearing the camera. The families contacted had previously taken part in a survey-based study; therefore, although they agreed to be contacted for future studies, they may have been happy to take part only in other survey-based research. The sample size was small and comprised mainly white and university-educated participants, which limits our ability to generalize the findings.

\section{Implications and Recommendations}

Taken together, the findings suggest that the SenseCam may be particularly useful for assessing behavioral aspects of the home environment and understanding how individuals interact with their home environment more generally, while home visits may be needed to more rigorously assess the availability of food and media equipment. A future study could directly compare SenseCam images with the results of home visits.

Having a longer wearing period or having multiple family members wear a SenseCam might provide a more comprehensive picture of the home environment. Most participants felt that 4 days was sufficient, so some form of incentive might be needed for a longer wearing period. Offering an incentive may also encourage less motivated, harder-to-reach families to take part in future studies, and it may minimize data loss if participants are motivated to keep the camera on for longer. In this study, participants were asked to remove the camera whenever they went outside of the home environment to minimize the chance of certain ethical issues arising and because it wasn't necessary for participants to wear the camera outside. However, future research could have participants wear the camera outside of the home environment, as previous research has done [19,20], provided that certain ethical issues are taken into consideration. The SenseCam was considered unsuitable for young children to wear, although older children could wear one.

Using a device that can capture higher quality images would also benefit future research. Since the start of this study, the SenseCam has been superseded with newer models that can capture indoor images to a higher standard. Asking participants to clarify certain images may also help to minimize data loss.

\section{Conclusions}

This study found that a wearable camera can be used to examine and validate aspects of the obesogenic home environment. While the SenseCam can capture physical aspects of the home environment such as food availability, its added strength is in capturing behavior. An optimal validation procedure could use a combination of home visits and wearable cameras.

\section{Acknowledgments}

We would like to thank Dr Paul Kelly and Dr Aiden Doherty for their advice and expertise on using the SenseCam and the SenseCam steering committee for loaning the cameras. This work was supported by Cancer Research UK and an IMPACT studentship awarded to SS. The studentship was partly funded by University College London and partly funded by the charity Weight Concern. The study sponsors had no role in the study design; collection, analysis, and interpretation of data; writing the report; or the decision to submit the report for publication. No financial disclosures were reported by the authors of this paper. 


\section{Conflicts of Interest}

None declared.

\section{Multimedia Appendix 1}

Home environment features as assessed in the Home Environment Interview.

[PDF File (Adobe PDF File), 54KB-Multimedia Appendix 1]

\section{References}

1. Davison KK, Birch LL. Childhood overweight: a contextual model and recommendations for future research. Obes Rev 2001;2(3):159-171 [FREE Full text] [Medline: 12120101]

2. Ebbeling CB, Pawlak DB, Ludwig DS. Childhood obesity: public-health crisis, common sense cure. Lancet 2002;360(9331):473-482. [doi: 10.1016/S0140-6736(02)09678-2] [Medline: 12241736]

3. Golan M. Parents as agents of change in childhood obesity —-from research to practice. Int J Pediatr Obes 2006;1(2):66-76. [Medline: 17907317$]$

4. Gattshall ML, Shoup JA, Marshall JA, Crane LA, Estabrooks PA. Validation of a survey instrument to assess home environments for physical activity and healthy eating in overweight children. Int J Behav Nutr Phys Act 2008;5:3 [FREE Full text] [doi: 10.1186/1479-5868-5-3] [Medline: 18190709 ]

5. Pinard CA, Yaroch AL, Hart MH, Serrano EL, McFerren MM, Estabrooks PA. Measures of the home environment related to childhood obesity: a systematic review. Public Health Nutr 2012;15(1):97-109. [doi: 10.1017/S1368980011002059] [Medline: 21899786]

6. Schrempft S, van Jaarsveld CHM, Fisher A, Wardle J. The obesogenic quality of the home environment: associations with diet, physical activity, TV viewing, and BMI in preschool children. PLoS One 2015;10(8):e0134490 [FREE Full text] [doi: 10.1371/journal.pone.0134490] [Medline: 26248313]

7. Bryant MJ, Ward DS, Hales D, Vaughn A, Tabak RG, Stevens J. Reliability and validity of the Healthy Home Survey: a tool to measure factors within homes hypothesized to relate to overweight in children. Int J Behav Nutr Phys Act 2008;5:23 [FREE Full text] [doi: 10.1186/1479-5868-5-23] [Medline: 18442392]

8. Sisk C, Sharkey JR, McIntosh WA, Anding J. Using multiple household food inventories to measure food availability in the home over 30 days: a pilot study. Nutr J 2010;9:19 [FREE Full text] [doi: 10.1186/1475-2891-9-19] [Medline: 20398314]

9. Crittenden PM, Bonvillian JD. The relationship between maternal risk status and maternal sensitivity. Am J Orthopsychiatry 1984;54(2):250-262. [Medline: 6731591]

10. Gunning M, Conroy S, Valoriani V, Figueiredo B, Kammerer MH, Muzik M, et al. Measurement of mother-infant interactions and the home environment in a European setting: preliminary results from a cross-cultural study. Br J Psychiatry 2004;184(46):s38-s44. [Medline: 14754817 ]

11. Wilson P, Puckering C, McConnachie A, Marwick H, Reissland N, Gillberg C. Inexpensive video cameras used by parents to record social communication in epidemiological investigations in early childhood: a feasibility study. Infant Behav Dev 2011;34(1):63-71. [doi: 10.1016/j.infbeh.2010.09.007] [Medline: 21036401]

12. Briggs L, Lake AA. Exploring school and home food environments: perceptions of 8-10-year-olds and their parents in Newcastle upon Tyne, UK. Public Health Nutr 2011;14(12):2227-2235. [doi: 10.1017/S1368980011001984] [Medline: 21859512]

13. Bell G, Gemmell J. A digital life. Sci Am 2007;296(3):58-65. [doi: 10.1038/scientificamerican0307-58]

14. Loveday A, Sherar LB, Sanders JP, Sanderson PW, Esliger DW. Technologies that assess the location of physical activity and sedentary behavior: a systematic review. J Med Internet Res 2015;17(8):e192 [FREE Full text] [doi: 10.2196/jmir.4761] [Medline: 26245157]

15. Hodges S, Williams L, Berry E, Izadi S, Srinivasan J, Butler A, et al. SenseCam: A Retrospective Memory Aid. In: Dourish P, Friday A, editors. UbiComp 2006: Ubiquitous Computing. Berlin: Springer; 2006:177-193.

16. Microsoft. SenseCam. URL: https://www.microsoft.com/en-us/research/project/sensecam/?from=http $\% 3 \mathrm{~A} \% 2 \mathrm{~F} \% 2 \mathrm{Fresearch}$. microsoft.com\%2Fen-us\%2Fum\%2Fcambridge\%2Fprojects\%2Fsensecam\%2Fgallery.htm [accessed 2017-02-28] [WebCite Cache ID 6ocBkRddM]

17. Berry E, Hampshire A, Rowe J, Hodges S, Kapur N, Watson P, et al. The neural basis of effective memory therapy in a patient with limbic encephalitis. J Neurol Neurosurg Psychiatry 2009;80(11):1202-1205. [doi: 10.1136/jnnp.2008.164251] [Medline: 19286742]

18. Pauly-Takacs K, Moulin CJA, Estlin EJ. SenseCam as a rehabilitation tool in a child with anterograde amnesia. Memory 2011;19(7):705-712. [doi: 10.1080/09658211.2010.494046] [Medline: 20658434]

19. Kelly P, Doherty A, Berry E, Hodges S, Batterham AM, Foster C. Can we use digital life-log images to investigate active and sedentary travel behaviour? Results from a pilot study. Int J Behav Nutr Phys Act 2011;8:44 [FREE Full text] [doi: 10.1186/1479-5868-8-44] [Medline: 21599935] 
20. Kelly P, Doherty AR, Hamilton A, Matthews A, Batterham AM, Nelson M, et al. Evaluating the feasibility of measuring travel to school using a wearable camera. Am J Prev Med 2012;43(5):546-550 [FREE Full text] [doi: 10.1016/j.amepre.2012.07.027] [Medline: 23079179]

21. O'Loughlin G, Cullen SJ, McGoldrick A, O'Connor S, Blain R, O'Malley S, et al. Using a wearable camera to increase the accuracy of dietary analysis. Am J Prev Med 2013;44(3):297-301. [doi: 10.1016/j.amepre.2012.11.007] [Medline: 23415128]

22. Gemming L, Doherty A, Kelly P, Utter J, Ni MC. Feasibility of a SenseCam-assisted 24-h recall to reduce under-reporting of energy intake. Eur J Clin Nutr 2013;67(10):1095-1099. [doi: 10.1038/ejcn.2013.156] [Medline: 24002044]

23. Kerr J, Marshall SJ, Godbole S, Chen J, Legge A, Doherty AR, et al. Using the SenseCam to improve classifications of sedentary behavior in free-living settings. Am J Prev Med 2013;44(3):290-296. [doi: 10.1016/j.amepre.2012.11.004] [Medline: 23415127]

24. Gemming L, Doherty A, Utter J, Shields E, Ni MC. The use of a wearable camera to capture and categorise the environmental and social context of self-identified eating episodes. Appetite 2015;92:118-125. [doi: 10.1016/j.appet.2015.05.019] [Medline: 26002278]

25. Cowburn G, Matthews A, Doherty A, Hamilton A, Kelly P, Williams J, et al. Exploring the opportunities for food and drink purchasing and consumption by teenagers during their journeys between home and school: a feasibility study using a novel method. Public Health Nutr 2016;19(1):93-103. [doi: 10.1017/S1368980015000889] [Medline: 25874731]

26. Kelly P, Marshall SJ, Badland H, Kerr J, Oliver M, Doherty AR, et al. An ethical framework for automated, wearable cameras in health behavior research. Am J Prev Med 2013;44(3):314-319. [doi: 10.1016/j.amepre.2012.11.006] [Medline: 23415131]

27. Doherty AR, Moulin CJA, Smeaton AF. Automatically assisting human memory: a SenseCam browser. Memory 2011;19(7):785-795. [doi: 10.1080/09658211.2010.509732] [Medline: 20845223]

28. Cicchetti DV. Guidelines, criteria, and rules of thumb for evaluating normed and standardized assessment instruments in psychology. Psychol Assess 1994;6(4):284-290. [doi: 10.1037/1040-3590.6.4.284]

29. Cicchetti DV, Feinstein AR. High agreement but low kappa: II. Resolving the paradoxes. J Clin Epidemiol 1990;43(6):551-558. [Medline: 2189948]

30. Aarts H, Dijksterhuis A. Habits as knowledge structures: automaticity in goal-directed behavior. J Pers Soc Psychol 2000;78(1):53-63. [Medline: 10653505]

\section{Abbreviations}

HEI: Home Environment Interview

ICC: intraclass correlation coefficient

pneg: proportion of negative agreement

ppos: proportion of positive agreement

Edited by G Eysenbach; submitted 25.03.17; peer-reviewed by F Alshaikh, J Utter, E Fradgley; comments to author 19.07.17; revised
version received 01.08.17; accepted 01.08.17; published 12.10 .17
Please cite as:
Schrempft $S$, van Jaarsveld CHM, Fisher A
Exploring the Potential of a Wearable Camera to Examine the Early Obesogenic Home Environment: Comparison of SenseCam
Images to the Home Environment Interview
J Med Internet Res $2017 ; 19(10):$ e332
URL: $\underline{\text { http://www.jmir.org/2017/10/e332/ }}$
doi: $\underline{10.2196 / j m i r .7748}$
PMID: 29025695

(CStephanie Schrempft, Cornelia HM van Jaarsveld, Abigail Fisher. Originally published in the Journal of Medical Internet Research (http://www.jmir.org), 12.10.2017. This is an open-access article distributed under the terms of the Creative Commons Attribution License (https://creativecommons.org/licenses/by/4.0/), which permits unrestricted use, distribution, and reproduction in any medium, provided the original work, first published in the Journal of Medical Internet Research, is properly cited. The complete bibliographic information, a link to the original publication on http://www.jmir.org/, as well as this copyright and license information must be included. 